\title{
Trigonocephaly-bifid nose-acral anomalies syndrome
}

INSERM

\section{Source}

INSERM. (1999). Orphanet: an online rare disease and orphan drug data base.

Trigonocephaly-bifid nose-acral anomalies syndrome. ORPHA:3368

Trigonocephaly-bifid nose-acral anomalies syndrome is characterized by trigonocephaly, brachycephaly, bulbous nose (bifid at the tip), micrognathia, macrostomia, hypotonia and relatively broad metatarsals and phalanges. There has been no further descriptions in the literature since 1991. 